\title{
PELAKSANAAN PASAL 4 AYAT (1) PERATURAN PEMERINTAH REPUBLIK INDONESIA NOMOR 11 TAHUN 2010 TENTANG PENERTIBAN DAN PENDAYAGUNAAN TANAH TERLANTAR DI KABUPATEN BLITAR
}

\author{
Anik Iftitah, \\ Fakultas Hukum Universitas Islam Balitar, \\ E-mail : geest_willdaad@yahoo.com; HP. 085646498763.
}

\begin{abstract}
ABSTRAKSI
Peraturan Pemerintah Republik Indonesia Nomor 11 Tahun 2010 tentang Penertiban dan Pendayagunaan Tanah Terlantar (PP 11/2010) dibentuk guna menyelesaikan persoalan penelantaran tanah di Indonesia. Namun, justru Perkebunan Kismo Handayani di Kabupaten Blitar sebagai tanah yang masuk database tanah terindikasi terlantar, justru mengalami puncak konflik pasca pelaksanaan PP 11/2010. Hal tersebut melatarbelakangi peneliti untuk meneliti pelaksanaan dan akibat pelaksanaan Pasal 4 Ayat (1) PP 11/2010 di Kabupaten Blitar. Penelitian hukum empiris di Perkebunan Kismo Handayani di Desa Soso Kecamantan Gandusari Kabupaten Blitar menggunakan teori sistem hukum, menunjukkan bahwa pelaksanaan Pasal 4 Ayat (1) PP 11/2010 di Kabupaten Blitar, menjadikan tanah sengketa sebagai indikator tanah terindikasi terlantar (suatu pengindikasian tanah terindikasi terlantar yang tidak sesuai dengan substansi PP 11/2010), berakibat terhentinya pelaksanaan PP 11/2010 pada tahap identifikasi dan penelitian, tidak ada satupun hak atas tanah di Kabupaten Blitar yang ditetapkan oleh Kepala BPN-RI sebagai tanah terlantar, ketidakjelasan status hukum hak atas tanah Perkebunan Kismo Handayani selama \pm 6 tahun ( 2011-2016 ), dan memuncaknya ekskalasi konflik di area eks-HGU Perkebunan Kismo Handayani pada rentang waktu Tahun 2011-2016 yang pada akhirnya diatasi dengan redistribusi dan penerbitan sertifikat HGU atas nama Kismo Handayani pada tahun 2017. Hasil penelitian ini patut dijadikan bahan refleksi. Tertib maupun konflik, merupakan akibat pelaksanaan (substansi) hukum yang sangat bergantung pada pelaksana hukum yang akan berimplikasi pada wujud budaya hukum masyarakat.
\end{abstract}

Kata kunci : Pelaksanaan Hukum, Tanah Terindikasi Terlantar, Konflik Agraria

\begin{abstract}
The Government Regulation of the Republic of Indonesia Number 11 Year 2010 on the Control and Utilization of Abandoned Land (PP 11/2010) was formed to solve the problem of land abandonment in Indonesia. However, instead of Kismo Handayani Plantation in Blitar Regency as land that was indicated as abandoned land, it experienced peak of conflict after implementation of PP 11/2010. It was the background of the researchers to examine the implementation and the result of the implementation of Article 4 Paragraph (1) PP 11/2010 in Blitar Regency. Empirical legal research at Kismo Handayani Plantation in Soso Village, Gandusari Distric, Blitar Regency used the theory of legal system, indicating that the implementation of Article 4 Paragraph (1) PP 11/2010 in Blitar Regency, making the land dispute as indicator of land indicated neglected (an indication indicated abandoned land not in accordance with the substance of PP 11/2010), resulted in the cessation of the implementation of PP 11/2010 at the stage of identification and research; there was no single right to land in Blitar Regency as stipulated by the Head of BPN-RI as abandoned land; the vagueness of the legal status of land rights Kismo Handayani Plantation as long as 6 years ( 2011 2016 ), and mounting escalation of the conflict in the former concession area of Kismo Handayani Plantation who eventually overcome by redistribution and inssuance of Kismo Handayani certificate in 2017. The results of this research should be used as a reflection material. Order and conflict, is the result of the implementation (substance) of the law that is highly dependent on legal structure which will have implications in the form of legal culture community.
\end{abstract}

Keywords: Implementation of Law, Abandoned Land, Agrarian Conflict 


\section{PENDAHULUAN}

Tanah adalah karunia Tuhan bagi rakyat, bangsa dan negara Indonesia, yang harus diusahakan, dimanfaatkan, dan dipergunakan untuk sebesar-besarnya kemakmuran rakyat. Namun, saat ini tanah yang telah dikuasai dan/atau dimiliki, baik yang sudah ada hak atas tanahnya maupun yang baru berdasar perolehan tanah, di beberapa tempat masih banyak dalam keadaan terlantar. Tanah terlantar berdasarkan Peraturan Pemerintah Republik Indonesia Nomor 11 tahun 2010 (PP 11/2010) tentang Penertiban dan Pendayagunaan Tanah Terlantar merupakan tanah yang sudah dilekati hak oleh negara atau memiliki dasar penguasaan tanah, yang tidak diusahakan, tidak dipergunakan atau tidak dimanfaatkan sesuai dengan keadaan atau sifat dan tujuan pemberian hak atau dasar penguasaannya. Sejauh ini, hasil inventarisasi oleh Badan Pertanahan Nasional Republik Indonesia (BPN-RI) menunjukkan bahwa terdapat sekitar 7,3 juta hektar tanah terindikasi terlantar. ${ }^{1}$

Pemerintah Indonesia guna mengatasi masalah seperti tersebut di atas, melakukan pengaturan melalui PP 11/2010, agar tanah terindikasi terlantar seluas tersebut di atas didayagunakan untuk pelaksanaan reforma agraria (redistribusi), program strategis negara (penciptaan lahan pangan, energi, dan perumahan rakyat), dan cadangan negara lainnya (kepentingan pemerintah, hankam, dan relokasi bencana alam).

Namun, kepastian kedayagunaan (efficacy) hasil penertiban dan pendayagunaan tanah terlantar sebagai salah satu potensi objek reforma agraria demi berfungsinya tanah untuk kesejahteraan rakyat, belum nyata terbukti secara real di wilayah Kabupaten Blitar, Jawa Timur. Kabupaten Blitar merupakan suatu daerah di Jawa Timur, yang selalu kaya dengan persoalan dan perjuangan keagrariaan. Tahun 2013, Kantor Pertanahan Kab. Blitar mencatat ada 27 titik sengketa dan konflik perkebunan tipologi sengketa penguasaan dan pemilikan antara perusahaan perkebunan pemegang Hak Guna Usha (HGU) dengan masyarakat sekitar areal HGU. Di Kabupaten Blitar, tanah terindikasi terlantar dengan HGU total luasannya adalah 579 ha dan data base tanah terindikasi terlantar dengan dasar penguasaan (Ijin Lokasi) seluas 511, 0739 ha.

Keberadaan PP 11/2010 tidak mampu mewujudkan maksud keberadaannya guna menghapuskan tanah sebagai salah satu sumber sengketa dan konflik di Kabupaten Blitar. Kasus konflik pertanahan di Perkebunan Kismo Handayani yang terletak di Desa Soso, Kec. Gandusari, Kab. Blitar, Jawa Timur sebagai tanah terindikasi terlantar justru memuncak pada tahun 2012, pasca diberlakukannya PP 11/2010. ${ }^{2}$ Perkebunan Kismo Handayani merupakan salah satu tanah yang didata oleh Kantor Pertanahan Kab. Blitar sebagai tanah terindikasi terlantar pada tahun 2010. PP 11/2010 sebagai produk hukum yang semestinya mampu mewujudkan ketertiban, faktanya malah terjadi peningkatan ekskalasi konflik di atas tanah terindikasi terlantar sebagai bagian dari obyek

${ }^{1}$ Dicky Firmansyah, "Pendayagunaan Tanah Terlantar untuk Kesejahteraan Rakyat", Bhumi, Jurnal Ilmiah Pertanahan PPPM-STPN, Nomor 3 Tahun 2, September 2010, 2010, hal. 2.

2 Pada Juni 2012, sekelompok masyarakat Desa Soso, Kec. Gandusari, Kab. Blitar, melakukan reclaiming, menduduki dan menempati, menebangi pohon-pohon perkebunan yang masih produktif dan melakukan penghancuran di areal perkebunan Kismo Handayani, Desa Soso, Kec. Gandusari, Kab. Blitar sehingga aktivitas perusahaan pada saat itu, menjadi lumpuh total. 
pengaturannya. Hal itulah yang melatarbelakangi peneliti untuk meneliti pelaksanaan dan akibat pelaksanaan Pasal 4 Ayat (1) PP 11/2010 di Kabupaten Blitar.

\section{METODE PENELITIAN}

Untuk menjawab permasalahan yang telah dirumuskan dalam penelitian ini, digunakan penelitian hukum empiris. Penelitian ini dilakukan di Kabupaten Blitar yang merupakan salah satu kabupaten yang mempunyai areal tanah terindikasi terlantar. Untuk memperdalam permasalahan akar rumput, maka penelitian ini difokuskan di Perkebunan Kismo Handayani ${ }^{3}$ di Desa Soso Kecamantan Gandusari Kabupaten Blitar.

\section{Gambar Lokasi Penelitian (Perkebunan Kismo Handayani, Kab. Blitar)}

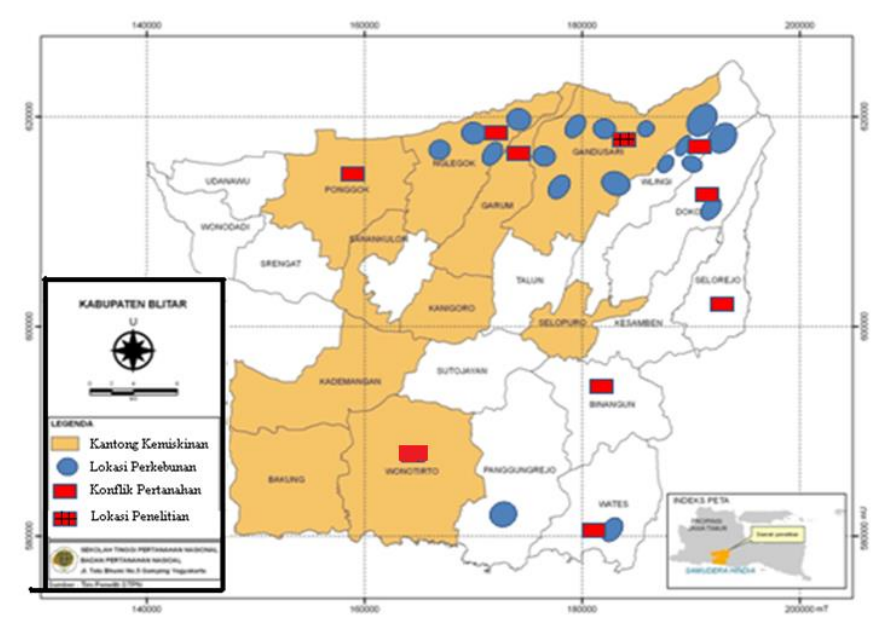

Penelitian ini dilakukan selama enam bulan yang terbagi menjadi bagian yakni studi kepustakaan dan field work. Field work dilakukan pada bulan Januari-Februari 2017. Teknik penggalian data yang digunakan dalam kerja lapangan adalah direct observation, dokumentasi dan indepth interview. Observasi langsung dilakukan di areal Perkebunan Nyunyur. Wawancara mendalam dilakukan kepada di Kantor Pertanahan Kabupaten Blitar, Pemerintah Daerah Kabupaten Blitar, pihak Dinas Perkebunan, Pemerintah dan tokoh masyarakat Desa Soso, Kec. Gandusari, Kab. Blitar.

Data yang telah terkumpul baik dari hasil penelitian lapangan (data primer) maupun penelitian kepustakaan (data sekunder) selanjutnya diolah dan dianalisis secara kualitatif. Pada tahap pengolahan, data yang telah terkumpul dikategorikan dan dikualifikasikan berdasarkan permasalahan penelitian, selanjutnya disusun secara sistematis sesuai dengan kerangka yang telah disiapkan sebelumnya. Pada tahap analisis, data yang telah dikategorikan dan dikualifikasi dianalisis dengan mengaitkan data satu dengan data lainnya, yaitu dengan mencocokan, membandingkan, mengelompokan dan verifikasi data agar sebuah fenomena memiliki nilai yuridis, akademis dan ilmiah. Selanjutnya diadakan penafsiran data untuk dapat menghasilkan simpulan tentang permasalahan yang diajukan. Kemudian keseluruhan hasil analisis, selanjutnya disajikan secara deskriptif,

${ }^{3}$ Perkebunan Kismo Handayani, lazim pula dikenal masyarakat Blitar dengan nama Perkebunan Nyunyur. Perkebunan Nyunyur alis Perkebunan Kismo Handayani sebelum 1985 milik PT. Nyunyur Baru dan pasca 1985 PT. Nyunyur Baru berganti nama menjadi PT. Kismo Handayani, sehingga dalam tulisan ini, peneliti menggunakan istilah penyebutan Perkebunan Kismo Handayani dalam penyebutan Perkebunan Nyunyur alias Perkebunan Kismo Handayani. 
yaitu dengan memaparkan secara lengkap segala persoalan yang terkait dengan masalah yang diteliti disertai dengan memberikan usulan-usulan secara kritis.

\section{PASAL 4 AYAT (1) PERATURAN PEMERINTAH REPUBLIK INDONESIA NOMOR 11 TAHUN 2010 TENTANG PENERTIBAN DAN PENDAYAGUNAAN TANAH TERLANTAR}

Pasal 4 ayat (1) PP 11/2010 yang berbunyi “ Kepala Kantor Wilayah menyiapkan data tanah yang terindikasi terlantar", pelaksanaannya menjadi kunci utama dari pelaksanaan PP 11/2010 secara keseluruhan, karena pasal 4 ayat (1) merupakan tindakan awal dan utama sebagai penentu langkah-langkah penertiban dan pendayagunaan tanah terlantar selanjutnya.

PP 11/2010 lahir sebagai pelaksanaan amanat pasal 27 UUPA Tahun 1960, yang menegaskan bahwa tanah yang ditelantarkan diambil kembali oleh negara. ${ }^{4}$ Batang tubuh PP 11/2010 terdiri dari 20 (dua puluh) pasal dalam 8 (delapan) bab, yaitu BAB I Ketentuan Umum; Bab II Obyek Penertiban Tanah Terlantar; Bab III Identifikasi dan Penelitian; Bab IV Peringatan; Bab V Penetapan Tanah Terlantar; Bab VI Pendayagunaan Tanah Negara Bekas Tanah Terlantar; Bab VII Ketentuan Peralihan; dan Bab VIII Ketentuan Penutup.

Pengertian tanah terlantar pada Penjelasan Pasal 2 PP 11/2010, yaitu apabila tanahnya: a. tidak diusahakan; b; tidak dipergunakan atau c. tidak dimanfaatkan sesuai dengan keadaan atau sifat dan tujuan haknya. d. tanah yang ada dasar penguasaannya apabila tanahnya: tidak dimohon hak; tidak diusahakan; atau tidak dipergunakan; atau tidak dimanfaatkan sesuai dengan persyaratan atau ketentuan yang ditetapkan dalam izin lokasi, surat keputusan pemberian hak, surat keputusan pelepasan kawasan hutan, dan/atau dalam izin/keputusan/surat lainnya dari pejabat yang berwenang. Objek tanah terlantar yaitu tanah HGU baik yang subjeknya Perseorangan maupun Badan Hukum yang didirikan menurut hukum Indonesia dan berkedudukan di Indonesia; Tanah Hak Pakai; Tanah HGB yang pemegang haknya perorangan dan mempunyai kemampuan dari segi ekonomi untuk mengusahakan, menggunakan dan memanfaatkan tanah akan tetapi dengan sengaja tidak mempergunakan tanah sesuai dengan keadaan atau sifat dan tujuan pemberian haknya; tanah HGB yang pemegang haknya berupa Badan Hukum (Perseroan Terbatas); tanah yang dikuasai pemerintah (tanah asset pemerintah) dan mempunyai cukup anggaran untuk mengusahakan, menggunakan dan memanfaatkan tanah akan tetapi dengan sengaja tidak mempergunakan tanah sesuai dengan keadaan atau sifat dan tujuan pemberian haknya; tanah Hak Pengelolaan; dan tanah-tanah yang dikuasai oleh pihak yang telah memperoleh dasar penguasaan atas tanah [izin/keputusan/surat dari pejabat yang berwenang yang menjadi dasar penguasaan atas tanah] tetapi belum memperoleh hak atas tanah sesuai ketentuan peraturan perundang-undangan yang berlaku. Dalam Pasal 3 PP 11/2010 dirumuskan kriteria tanah yang tidak termasuk objek penertiban tanah terlantar, yaitu tanah hak milik atau Hak Guna Bangunan (HGB) atas nama perseorangan yang secara tidak sengaja tidak dipergunakan sesuai dengan keadaan atau sifat dan tujuan pemberian haknya; dan tanah yang dikuasai pemerintah baik secara langsung maupun tidak langsung dan sudah berstatus maupun belum berstatus Barang

\footnotetext{
${ }^{4}$ Dicky Firmansyah, loc.cit.
} 
Milik Negara/Daerah yang tidak sengaja tidak dipergunakan sesuai dengan keadaan atau sifat dan tujuan pemberian haknya.

Tanah yang terindikasi terlantar berdasarkan hasil inventarisasi dan telah ditetapkan sebagai target, dilakukan identifikasi dari aspek administrasi dan dilakukan penelitian lapang (fisik tanah). Selanjutnya, disusun dan ditetapkan target identifikasi dan penelitian tanah yang terindikasi terlantar, kemudian pemberitahuan dan sekaligus memberikan Peringatan Tertulis I sampai III kepada Pemegang Hak, agar dalam jangka waktu 1 (satu) bulan sejak tanggal diterbitkannya Surat Peringatan, menggunakan tanahnya sesuai keadaannya atau menurut sifat dan tujuan pemberian haknya atau sesuai izin/keputusan/surat sebagai dasar penguasaannya, dan kalau tidak, maka dapat berlanjut pada penetapan sebagai tanah terlantar atas tanah tersebut.

\section{Pelaksanaan Pasal 4 Ayat (1) Peraturan Pemerintah Republik Indonesia Nomor 11 Tahun 2010 tentang Penertiban dan Pendayagunaan Tanah Terlantar di Kabupaten Blitar}

Pelaksana Pasal 4 Ayat (1) Peraturan Pemerintah Republik Indonesia Nomor 11 Tahun 2010 tentang Penertiban dan Pendayagunaan Tanah Terlantar (PP 11/2010) di Kabupaten Blitar adalah Badan Pertanahan Nasional (BPN) Kabupaten Blitar, yang menurut teori legal system disebut sebagai legal structure. Penelitian pelaksanaan Pasal 4 Ayat (1) PP 11/2010 ini, merupakan penelitian hukum empiris dengan teori sistem hukum yang berpangkal dan/atau terlengkapkan oleh paradigma positivisme hukum, pragmatic legal realism dan sosiological jurisprudens.

Pasal 4 ayat (1) PP 11/2010 menyatakan bahwa, "Kepala Kantor Wilayah menyiapkan data tanah yang terindikasi terlantar". Maksudnya adalah, inventarisasi tanah terindikasi terlantar dilakukan oleh Kepala Kantor Wilayah BPN Provinsi Jawa Timur berdasarkan informasi yang diperoleh dari hasil pemantauan lapangan oleh Kepala Kantor Pertanahan Kabupaten Blitar. Terhadap tanah-tanah di Kabupaten Blitar yang mempunyai indikasi terlantar, maka BPN Kabupaten Blitar melakukan pemantauan lapangan. Selanjutnya, Kepala Kantor Wilayah BPN Provinsi berdasarkan informasi yang diperoleh dari hasil pemantauan lapangan oleh Kepala Kantor Pertanahan Kabupaten Blitar melakukan inventarisasi tanah terindikasi terlantar.

Kegiatan inventarisasi tanah terindikasi terlantar di Kabupaten Blitar, menghasilkan database tanah terindikasi terlantar di Kab. Blitar pada tahun 2010 dengan total luasan $3.601,4639$ ha dengan pemegang hak yang meliputi 9 perkebunan swasta, 1 perkebunan negara, 2 militer, dan 12 Perhutani. 
Tabel Data Awal Tanah yang Terindikasi Terlantar Sampai dengan Tahun 2010 Kab. Blitar Prov. Jawa Timur

\begin{tabular}{|c|c|c|c|c|}
\hline No. & Nama Pemegang Hak & $\begin{array}{l}\text { Jenis Hak/Dasar } \\
\text { Penguasaan }\end{array}$ & Luas & $\begin{array}{c}\text { Luasan } \\
\text { Tanah yang } \\
\text { Terindikasi } \\
\text { Terlantar }\end{array}$ \\
\hline 1. & $\begin{array}{l}\text { PT. BLITAR PUTRA, } \\
\text { Gadungan, Gandusari }\end{array}$ & HGU & 386.4000 & 80.0000 \\
\hline 2. & $\begin{array}{l}\text { PT. ROTOREJO, Gadungan, } \\
\text { Sumberagung, Gandusari }\end{array}$ & SK Hak & $\begin{array}{l}464.9720 \\
92.2550\end{array}$ & 53.0000 \\
\hline 3. & $\begin{array}{l}\text { PT. Kismo Handayani, Soso, } \\
\text { Gandusari }\end{array}$ & HGU & 368.0000 & 26.0000 \\
\hline 4. & $\begin{array}{l}\text { PT. Sari Bumi Kawi, Suber } \\
\text { Urip, Doko }\end{array}$ & HGU & 955.5000 & 255.0000 \\
\hline 5. & $\begin{array}{l}\text { PT. Veteran Sri, Modangan, } \\
\text { Nglegok }\end{array}$ & HGU & $\begin{array}{l}165.0000 \\
58.9375\end{array}$ & 200.0000 \\
\hline 6. & PTPN XII, Penataran, Nglegok & HGU & 328.6600 & 70.0000 \\
\hline 7. & $\begin{array}{l}\text { PT. Setia Mukti Raya, } \\
\text { Karangrejo, Garum }\end{array}$ & HGU & 612.0000 & 150.0000 \\
\hline 8. & $\begin{array}{ll}\text { PT. NV Perkebunan } & \text { dan } \\
\text { Perdagangan Dewi } & \text { Sri, } \\
\text { Ngadirenggo, Wlingi } & \\
\end{array}$ & HGU & $\begin{array}{l}319.6450 \\
198.1030\end{array}$ & 180.0000 \\
\hline 9. & $\begin{array}{l}\text { PT. Tri Windu, Ngadirenggo, } \\
\text { Wlingi }\end{array}$ & HGU & $\begin{array}{l}174.4200 \\
185.6700 \\
\end{array}$ & 50.0000 \\
\hline 10. & $\begin{array}{l}\text { PT. Semen Dwima Agung, } \\
\text { Ringinrejo, Wates }\end{array}$ & HGU & $\begin{array}{l}56.7380 \\
287.1900 \\
\end{array}$ & 50.0000 \\
\hline 11. & $\begin{array}{l}\text { Puskopad, Ngeni dan } \\
\text { Ngadipuro Kec. Wonotirto } \\
\text { dan Serang-Pangunggrejo }\end{array}$ & Tanah erfpacht & 2.117 .4990 & 511.0739 \\
\hline 12. & $\begin{array}{l}\text { Dephankam Cq TNI AU, } \\
\text { Pojok-Ponggok }\end{array}$ & Hak Pakai & $\begin{array}{l}17.8900 \\
15.0000\end{array}$ & $\begin{array}{l}17.8900 \\
15.0000\end{array}$ \\
\hline 13 & $\begin{array}{l}\text { PERHUTANI, Ampelgading, } \\
\text { Selorejo }\end{array}$ & Tanah Negara & - & 60.0000 \\
\hline 14 & $\begin{array}{l}\text { PERHUTANI, Ngadirenggo, } \\
\text { Wlingi }\end{array}$ & Tanah Negara & - & 100.000 \\
\hline 15 & $\begin{array}{l}\text { PERHUTANI, } \\
\text { Gandusari }\end{array}$ & Tanah Negara & - & 46.0000 \\
\hline 16 & $\begin{array}{l}\text { PERHUTANI, } \\
\text { Gandusari }\end{array}$ & Tanah Negara & - & 35.0000 \\
\hline 17 & $\begin{array}{l}\text { PERHUTANI, Plumbangan } \\
\text { Doko }\end{array}$ & Tanah Negara & - & 110.0000 \\
\hline 18 & $\begin{array}{l}\text { PERHUTANI, Banjarsari } \\
\text { Wonotirto }\end{array}$ & Tanah Negara & - & 213.0000 \\
\hline 19 & $\begin{array}{l}\text { PERHUTANI, Tambakrejo, } \\
\text { Wonotirto }\end{array}$ & $\begin{array}{l}\text { Tanah Negara } \\
\text { bekas hak barat } \\
\text { (Hak erfpacht) }\end{array}$ & - & 350.0000 \\
\hline 20 & $\begin{array}{l}\text { PERHUTANI, } \\
\text { Binangun }\end{array}$ & $\begin{array}{l}\text { Tanah Negara } \\
\text { bekas hak barat } \\
\text { (Hak erfpacht) }\end{array}$ & - & 525.0000 \\
\hline 21 & $\begin{array}{l}\text { PERHUTANI, } \\
\text { Gandusari }\end{array}$ & $\begin{array}{l}\text { Tanah Negara } \\
\text { bekas hak barat } \\
\text { (Hak erfpacht) }\end{array}$ & - & 18.5000 \\
\hline 22 & PERHUTANI, & Negara & - & 313.0000 \\
\hline
\end{tabular}




\begin{tabular}{|l|l|l|l|l|}
\hline & Wates & $\begin{array}{l}\text { bekas hak barat } \\
\text { (Hak erfpacht) }\end{array}$ & \\
\hline 23 & $\begin{array}{l}\text { PERHUTANI, Bululawang, } \\
\text { Bakung }\end{array}$ & $\begin{array}{l}\text { Tanah Negara } \\
\text { bekas hak barat } \\
\text { (Hak erfpacht) }\end{array}$ & - & 20.0000 \\
\hline 24 & $\begin{array}{l}\text { PERHUTANI, Pohgajih, } \\
\text { Selorejo }\end{array}$ & $\begin{array}{l}\text { Tanah Negara } \\
\text { bekas Pangonan }\end{array}$ & - & 137.0000 \\
\hline \multicolumn{4}{|r|}{ JUMLAH } & 3601.4639 \\
\hline
\end{tabular}

Sumber : Data Sekunder, Diolah, 2017

Database di atas menunjukkan bahwa dari 24 item tanah yang terindikasi terlantar sampai dengan tahun 2010 di Kab. Blitar, 13 item-nya (lebih dari 50 \% -nya) merupakan tanah negara. Jika database tersebut diperhatikan seksama, maka tanah yang terindikasi terlantar sampai dengan tahun 2010 Kab. Blitar merupakan tanah dengan tipikal sengketa dan konflik pertanahan di Kab. Blitar.

Tabel Tanah Terindikasi di Kab. Blitar - Tanah Sengketa

\begin{tabular}{|c|c|c|}
\hline No. & Nama Pemegang Hak Perkebunan & Tipologi \\
\hline 1. & $\begin{array}{l}\text { PT. BLITAR PUTRA, Gadungan, } \\
\text { Gandusari }\end{array}$ & $\begin{array}{lll}\begin{array}{l}\text { Sengketa } \\
\text { pemilikan }\end{array} & \text { penguasaan } & \text { dan } \\
\end{array}$ \\
\hline 2. & $\begin{array}{lcl}\text { PT. } & \text { ROTOREJO, } & \text { Gadungan, } \\
\text { Sumberagung, Gandusari } & \\
\end{array}$ & $\begin{array}{lll}\begin{array}{l}\text { Sengketa } \\
\text { pemilikan }\end{array} & \text { penguasaan } \\
\end{array}$ \\
\hline 3. & PT. Kismo Handayani, Soso, Gandusari & $\begin{array}{lll}\begin{array}{l}\text { Sengketa } \\
\text { pemilikan }\end{array} & \text { penguasaan } & \text { dan } \\
\end{array}$ \\
\hline 4. & PT. Sari Bumi Kawi, Suber Urip, Doko & $\begin{array}{lll}\begin{array}{l}\text { Sengketa } \\
\text { pemilikan }\end{array} & \text { penguasaan dan } \\
\end{array}$ \\
\hline 5. & PT. Veteran Sri, Modangan, Nglegok & $\begin{array}{lll}\begin{array}{l}\text { Sengketa } \\
\text { pemilikan }\end{array} & \text { penguasaan } & \text { dan } \\
\end{array}$ \\
\hline 6. & PTPN XII, Penataran, Nglegok & $\begin{array}{lll}\begin{array}{l}\text { Sengketa } \\
\text { pemilikan }\end{array} & \text { penguasaan } \\
\end{array}$ \\
\hline 7. & PT. Setia Mukti Raya, Karangrejo, Garum & penguasaan dan \\
\hline 8. & $\begin{array}{l}\text { PT. NV Perkebunan dan Perdagangan } \\
\text { Dewi Sri, Ngadirenggo, Wlingi }\end{array}$ & $\begin{array}{lll}\begin{array}{l}\text { Sengketa } \\
\text { pemilikan }\end{array} & \text { penguasaan } & \text { dan } \\
\end{array}$ \\
\hline 9. & PT. Tri Windu, Ngadirenggo, Wlingi & $\begin{array}{lll}\begin{array}{l}\text { Sengketa } \\
\text { pemilikan }\end{array} & \text { penguasaan dan } \\
\end{array}$ \\
\hline 10. & $\begin{array}{l}\text { PT. Semen Dwima Agung, Ringinrejo, } \\
\text { Wates }\end{array}$ & $\begin{array}{lll}\begin{array}{l}\text { Sengketa } \\
\text { pemilikan }\end{array} & \text { penguasaan } & \text { dan } \\
\end{array}$ \\
\hline 11. & $\begin{array}{l}\text { Puskopad, Ngeni dan Ngadipuro Kec. } \\
\text { Wonotirto dan Serang-Pangunggrejo }\end{array}$ & $\begin{array}{lll}\begin{array}{l}\text { Sengketa } \\
\text { pemilikan }\end{array} & \text { penguasaan dan } \\
\end{array}$ \\
\hline 12. & Dephankam Cq TNI AU, Pojok-Ponggok & $\begin{array}{l}\text { Sebagian telah diduduki dan } \\
\text { digarap oleh masyarakat }\end{array}$ \\
\hline 13. & PERHUTANI, Ampelgading, Selorejo & $\begin{array}{l}\text { Oleh Perhutani diklaim sebagai } \\
\text { Tanah Kawasan Hutan, tetapi telah } \\
\text { diduduki dan digarap oleh } \\
\text { masyarakat }\end{array}$ \\
\hline 14. & PERHUTANI, Ngadirenggo, Wlingi & $\begin{array}{l}\text { Oleh Perhutani diklaim sebagai } \\
\text { Tanah Kawasan Hutan, tetapi telah } \\
\text { diduduki dan digarap oleh } \\
\text { masyarakat }\end{array}$ \\
\hline 15 & PERHUTANI, Semen Gandusari & $\begin{array}{l}\text { Oleh Perhutani diklaim sebagai } \\
\text { Tanah Kawasan Hutan, tetapi telah } \\
\text { diduduki dan digarap oleh }\end{array}$ \\
\hline
\end{tabular}




\begin{tabular}{|c|c|c|}
\hline & & masyarakat \\
\hline 16 & PERHUTANI, Krisik Gandusari & $\begin{array}{l}\text { Oleh Perhutani diklaim sebagai } \\
\text { Tanah Kawasan Hutan, tetapi telah } \\
\text { diduduki dan digarap oleh } \\
\text { masyarakat }\end{array}$ \\
\hline 17 & PERHUTANI, Plumbangan Doko & $\begin{array}{l}\text { Oleh Perhutani diklaim sebagai } \\
\text { Tanah Kawasan Hutan, tetapi telah } \\
\text { diduduki dan digarap oleh } \\
\text { masyarakat }\end{array}$ \\
\hline 18 & PERHUTANI, Banjarsari Wonotirto & $\begin{array}{l}\text { Oleh Perhutani diklaim sebagai } \\
\text { Tanah Kawasan Hutan, tetapi telah } \\
\text { diduduki dan digarap oleh } \\
\text { masyarakat }\end{array}$ \\
\hline 19 & PERHUTANI, Tambakrejo, Wonotirto & $\begin{array}{l}\text { Oleh Perhutani diklaim sebagai } \\
\text { Tanah Kawasan Hutan, tetapi telah } \\
\text { diduduki dan digarap oleh } \\
\text { masyarakat }\end{array}$ \\
\hline 20 & PERHUTANI, Rejoso, Binangun & $\begin{array}{l}\text { Oleh Perhutani diklaim sebagai } \\
\text { Tanah Kawasan Hutan, tetapi telah } \\
\text { diduduki dan digarap oleh } \\
\text { masyarakat }\end{array}$ \\
\hline 21 & PERHUTANI, Semen Gandusari & $\begin{array}{l}\text { Oleh Perhutani diklaim sebagai } \\
\text { Tanah Kawasan Hutan, tetapi telah } \\
\text { diduduki dan digarap oleh } \\
\text { masyarakat }\end{array}$ \\
\hline 22 & PERHUTANI, Tulungrejo Wates & $\begin{array}{l}\text { Oleh Perhutani diklaim sebagai } \\
\text { Tanah Kawasan Hutan, tetapi telah } \\
\text { diduduki dan digarap oleh } \\
\text { masyarakat }\end{array}$ \\
\hline 23 & PERHUTANI, Bululawang, Bakung & $\begin{array}{l}\text { Oleh Perhutani diklaim sebagai } \\
\text { Tanah Kawasan Hutan, tetapi telah } \\
\text { diduduki dan digarap oleh } \\
\text { masyarakat }\end{array}$ \\
\hline 24 & PERHUTANI, Pohgajih, Selorejo & $\begin{array}{l}\text { Telah dikerjakan masyarakat sejak } \\
\text { tahun } 1921 \text { (zaman Belanda) }\end{array}$ \\
\hline
\end{tabular}

Sumber : Data Sekunder 2013, Diolah, 2017

Selanjutnya, data awal tanah yang terindikasi terlantar berdasarkan hasil inventarisasi, ditetapkan sebagai target, kemudian dilakukan identifikasi dari aspek administrasi dan dilakukan penelitian lapang (fisik tanah) oleh Panitia $\mathrm{C}$ yang dibentuk dan ditetapkan oleh Kepala Kantor Wilayah BPN Provinsi Jawa Timur. Setelah diperoleh data hasil identifikasi, Kepala Kantor Wilayah menyusun dan menetapkan target yang akan dilakukan identifikasi dan penelitian terhadap tanah yang terindikasi terlantar, sehingga menghasilkan data base tanah terindikasi terlantar dengan hak guna usaha total luasannya 579 ha dan data base tanah terindikasi terlantar dengan dasar penguasaan (Ijin Lokasi) seluas 511, 0739 ha.

Tabel Database Tanah Terindikasi Terlantar Kab. Blitar Pasca Identifikasi dan Penelitian

\begin{tabular}{|l|l|l|c|}
\hline No. & \multicolumn{1}{|c|}{ Nama Pemegang Hak } & \multicolumn{1}{|c|}{ Status Tanah } & Luas (Ha) \\
\hline 1. & PT. Rotorejo & HGU no.4,1 & 53.0000 \\
\hline 2 & PT. Kismo Handayani & HGU no.2 & 26.0000 \\
\hline 3 & PT. Veteran Sri & HGU no.3,5 & 200.0000 \\
\hline
\end{tabular}




\begin{tabular}{|l|l|l|c|}
\hline 4 & PTPN XII & HGU no.9 & 70.0000 \\
\hline 5 & $\begin{array}{l}\text { PT. NV Perkebunan dan } \\
\text { Perdangangan Dewi Sri }\end{array}$ & HGU no.8,12 & 180.0000 \\
\hline 6. & PT. Tri Windu & HGU no.10,11 & 50.0000 \\
\hline 7. & Puskopad Kodam V Brawijaya & Ijin Lokasi & 511.0739 \\
\hline
\end{tabular}

Sumber : Data Sekunder 2013, Diolah, 2017

\section{Akibat Pelaksanaan Pasal 4 Ayat (1) Peraturan Pemerintah Republik Indonesia Nomor 11 Tahun 2010 Tentang Penertiban dan Pendayagunaan Tanah Terlantar di Kabupaten Blitar}

PP 11/2010 sebagai substansi dalam teori sistem hukum menurut Friedmann yang diperkuat berdasarkan paradigma positivisme Hans Kelsen, merupakan sollen-skatagori (hukum sebagai keharusan), bukan seinskatagori (hukum sebagai kenyataan). Menjadikan indikator yang tidak sesuai dengan PP 11/2010 sebagai indikasi terlantarnya tanah (tidak sesuai dengan das sollen yang mesti dilaksanakan), akan mengakibatkan berurusan dengan akibat-akibat ketidaksesuainnya.

\subsection{Pelaksanaan Pasal 4 Ayat (1) PP Nomor 11 Tahun 2010 di Kab. Blitar, Terhenti pada Tahap Identifikasi dan Penelitian}

Menjadikan sengketa sebagai indikasi terlantarnya tanah sehingga masyarakat berkesempatan masuk untuk melakukan penggarapan yang berujung pada reclaiming, tidak sesuai dengan das sollen yang mesti dilaksanakan. Orang menaati hukum karena mereka memang harus menaati hukum sebagai perintah negara. Pelalaian terhadap perintah akan mengakibatkan berurusan dengan akibat-akibat kelalaiannya (sanksi).

Salah satu akibatnya adalah pelaksanaan Pasal 4 Ayat (1) PP 11/2010 di Kab. Blitar, menjadi berhenti pada tahap identifikasi dan penelitian, tidak bisa dilanjutkan pengupayaan penertibannya melalui penetapan sebagai tanah terlantar. Pengusulan penetapan tanah terlantar yang didasarkan pada identifikasi luasan dan pemegang hak atas tanah yang masuk dalam kategori sengketa dan konflik seperti yang dilakukan oleh Kantor Pertanahan Kab. Blitar tidak sesuai dengan PP 11/2010. Tanah dalam kategori sengketa dan konflik, tidak termasuk sebagai obyek penertiban tanah terlantar. Sekalipun tanah dalam status sengketa dan konflik juga tidak masuk dalam unsur tidak termasuk obyek penertiban tanah terlantar ${ }^{5}$, hal demikian tidak merubah ketidaksesuaian tanah bersengketa dan berkonflik dijadikan sebagai dasar pengkategorian tanah terlantar, mengingat asas legalitas ${ }^{6}$ di Indonesia sebagai negara hukum.

\subsection{Tidak Ada Satupun Hak Atas Tanah di Kabupaten Blitar yang Ditetapkan Berdasarkan SK Kepala BPN RI sebagai Tanah Terlantar}

Akibat dari proses pengajuan sebagaimana telah terjabarkan di atas, maka di Blitar tidak

5 Tidak termasuk obyek penertiban tanah terlantar adalah tanah Hak Milik atau Hak Guna Bangunan atas nama perseorangan yang secara tidak sengaja tidak dipergunakan sesuai dengan keadaan atau sifat dan tujuan pemberian haknya dan tanah yang dikuasai pemerintah baik secara langsung maupun tidak langsung dan sudah berstatus maupun belum berstatus Barang Milik Negara/Daerah yang tidak sengaja tidak dipergunakan sesuai dengan keadaan atau sifat dan tujuan pemberian haknya.

${ }^{6}$ Asas nullum delictum nulla poena sine praevia lege pornadi atau asa legalitas (Pasal 1 ayat 1 KUHPidana), yaitu tidak ada perbuatan yang dapat dihukum, kecuali sebelumnya ada UndangUndang yang mengaturnya. (Marwan Mas, Pengantar Ilmu Hukum, Jakarta : Ghalia Indonesia, 2004, hal. 97) 
ada satupun hak atas tanah yang ditetapkan berdasarkan SK Kepala BPN RI sebagai tanah terlantar. Tanah sengketa tidaklah sama dengan tanah terindikasi terlantar, karena untuk menuju pengidentifikasian tanah terlantar, tanah tersebut mesti clean and clear, bersih dari konflik/sengketa.

\subsection{Ketidakjelasan Status Hukum Hak Atas Tanah Perkebunan Kismo Handayani Selama \pm 6 Tahun ( 2011-2016 )}

Akibat dari Pelaksanaan Pasal 4 ayat (1) PP 11/2010, dimana stuktur (pelaksana) pemantau lapangan bertindak tidak sesuai dengan substansi (das sollen)-nya, juga berimbas pada kebelumjelasan jenis status hukum hak atas tanah Perkebunan Kismo Handayani sejak akhir 2010 sampai pada penelitian ini dilakukan, sehingga berimplikasi pada terbengkangkalainya areal perkebunan dari aktivitas perkebunan. Hak Guna Usaha (HGU) Perkebunan Kismo Handayani telah habis sejak Desember 2010, namun sampai pada Februari 2017, statusnya masih tetap dalam proses pengajuan perpanjangan HGU.
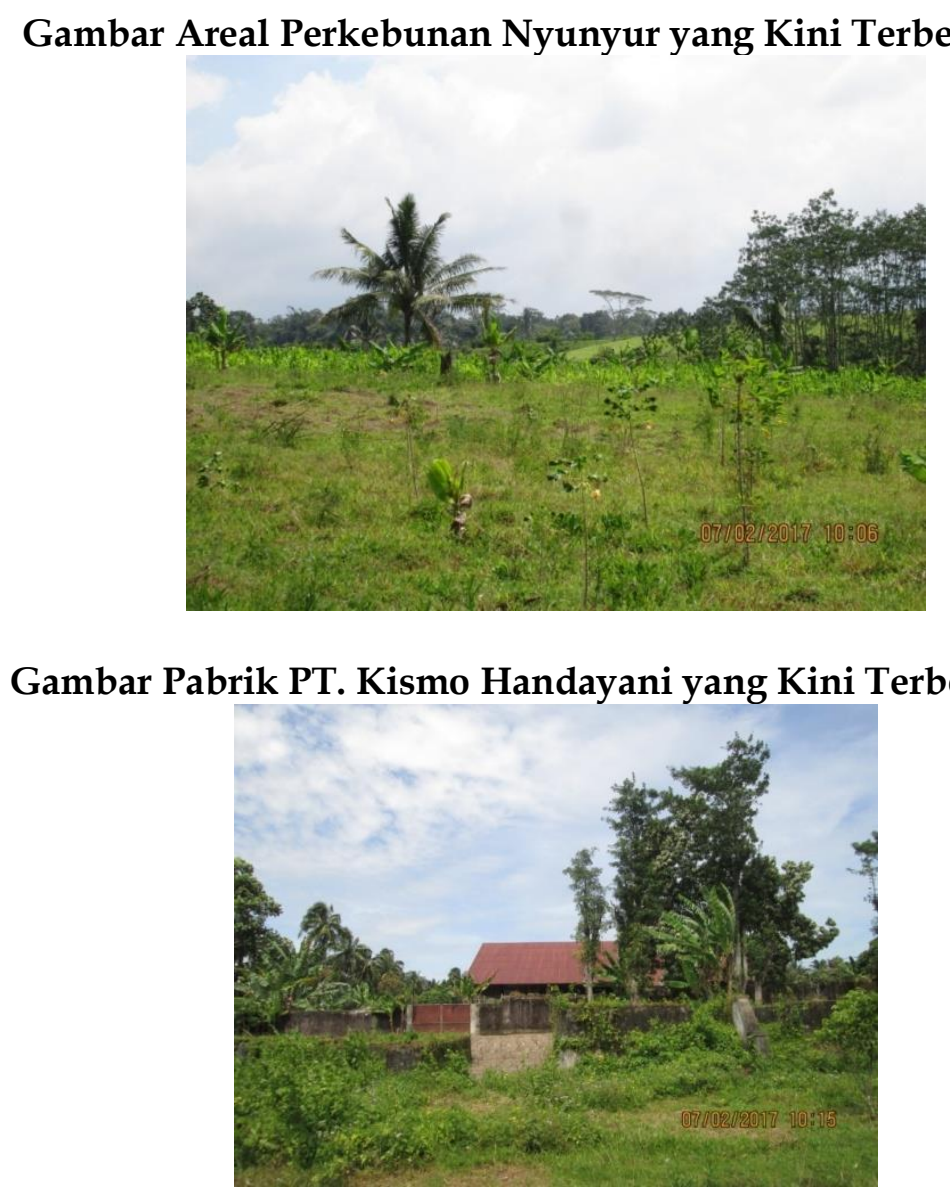

Sumber: Peneliti, foto diambil 7 Februari 2017

\subsection{Ekskalasi Konflik di Area eks-HGU Perkebunan Nyunyur PT. Kismo Handayani Memuncak Pada Rentang Waktu Tahun 2011-2016}

Lebih luasnya lagi, akibat pelaksanaan penertiban tanah di Kab. Blitar, juga memicu ekskalasi konflik di area eks-HGU Perkebunan Kismo Handayani. Ketidakjelasan status tanah HGU perkebunan yang sudah habis masa HGU-nya, kontan menimbulkan persepsi luas di kalangan masyarakat sekitar Desa Soso lokasi perkebunan, bahwa tanah areal HGU eks-perkebunan, secara otomatis menjadi tanah negara sehingga rakyat berhak untuk ikut 
serta menguasainya. Hal tersebut lazim memancing masalah oleh karena pada umumnya rakyat di sekitar kebun sangat membutuhkan lahan untuk menyambung kehidupannya. Ditambah lagi dengan perjalanan perjuangan agraria para petani sekitar perkebunan yang belum membuahkan hasil yang menuntut 26 ha tanah dalam HGU PT. Kismo Handayani untuk diberikan kepada rakyat berdasarkan SK Menteri Pertanian dan Agraria Nomor : 49/KA/1964 7 . Dipadu dengan belum jelasnya status hukum perkebunan pasca pelaksanaan PP 11/2010 di Kabupaten Blitar tersebut, akhirnya menjadikan areal Perkebunan Kismo Handayani ini mengalami berbagai konflik agraria.

\subsubsection{Konflik Agraria Horizontal}

Pada 15 Mei 2012, seorang warga Desa Soso beserta anaknya yang berada di Perkebunan Kismo Handayani yang tengah bekerja bakti dan mencari daun cengkeh kering untuk dijual, mengalami penendangan dan pemukulan sampai 2 (dua) gigi rontok, pengumpatan dan caci maki oleh seseorang yang melakukan pengklaimingan di areal perkebunan tersebut. ${ }^{8}$ Pada Rabu, 28 November 2012, seorang warga Desa Soso mengalami pemukulan hingga pingsan, dan pengancaman pembunuhan karena konflik pengklaiman/penggunaan tanah di areal PT. Kismo Handayani. ${ }^{9}$ Pada Rabu, tanggal 17 April 2013 terjadi pengancaman dengan senjata seperti tombak, pedang, clurit, dan senjata tajam lainnya terhadap warga Desa Soso karena konflik pengklaiman/penggunaan tanah di areal Kismo Handayani. ${ }^{10}$

\subsubsection{Konflik Agraria Perkebunan Kismo Handayani dalam Gambaran Media Massa}

1. TIMESINDONESIA, BLITAR pada Selasa, 1 Desember 2015 merilis berita akan aksi demontrasi di kantor Pemerintah Kab. Blitar (Pemkab Blitar) yang dilakukan oleh Front Perjuangan Petani Mataraman (FPPM) atas kondisi konflik agraria di Perkebunan Kismo Handayani yang terus mencekam. Warga yang menduduki areal HGU Perkebunan kerap dipanggil kepolisian karena diduga menguasai tanah tanpa ijin. Rumah-rumah warga di areal pendudukan, dirusak oleh oknum yang diduga berasal dari perusahaan perkebunan. ${ }^{11}$

2. Soerabaia Newsweek memberitakan bahwa terjadi aksi reklaming atas tanah yang dikelola oleh Perkebunan Kismo Handayani dengan melakukan penanaman tanaman pangan berupa singkong dan jagung. Ratusan warga Desa Soso, Kecamatan Gandusari, Kabupaten Blitar yang tergabung dalam Persatuan Pembebasan Tanah Nyunyur (Peptanyu), Namun, dapat dicegah oleh pihak aparat keamanan yang berjaga di lokasi

\footnotetext{
7 Berdasarkan SK Menteri Pertanian dan Agraria Nomor : 49/KA/1964, masyarakat Desa Soso Perkebunan Kismo Handayani memperoleh 100 ha tanah obyek land reform, telah dilaksanakan redistribusi, namun masyarakat merasa kurang 26 ha, sehingga areal seluas 26 ha wilayah HGU PT. Kismo Handayani diklaim oleh masyarakat sebagai kekurangan dari pelaksanaan redisribusi tahun 1964.

8 Arsip warga Desa Soso yang melaporkan kasus penganiayaannnya di Kadidpropam Polda Jatim pada tahun 2013.

${ }_{9}^{9}$ Arsip warga Desa Soso yang melaporkan kasus pemukulan dan pengancaman pembunuhan terhadap dirinya di Kadidpropam Polda Jatim pada 7 Juni 2013.

${ }^{10}$ Arsip salah satu Tokoh Masyarakat Pemerjuang Agraria di Desa Soso (Mbah Pawiro Podo) yang melaporkan kronologis konflik horizontal di Perkebunan Kismo Handayani di Kadidpropam Polda Jatim pada 7 Juni 2013

11 Blitar Times. http://www.timesindonesia.co.id/baca/110093/20151201/195351/fppm-tuntutlangkah-solutif-konflik-perkebunan-nyunyur/. Diakses pada 15 Februari 2017.
} 
perkebunan. Hal ini untuk mencegah bentrokan antara warga dengan pihak perkebunan. ${ }^{12}$

2.5 Upaya Pemerintah dalam Mengatasi Akibat Pelaksanaan Pasal 4 ayat (1) PP 11/2010 di Kabupaten Blitar

Sunaryati Hartono menyebutkan bahwa fungsi hukum antara lain sebagai pemeliharaan ketertiban dan keamanan, tidak terbukti oleh pelaksanaan Pasal 4 Ayat (1) PP 11/2010 di Kabupaten Blitar, karena pelaksanaannya yang tidak sesuai dengan substansi das sollennya, justru berakibat pada tidak adanya satupun hak atas tanah di Kab. Blitar yang ditetapkan Kepala BPN RI sebagai tanah terlantar, ketidakjelasan status hukum hak atas tanah Perkebunan Kismo Handayani (Perkebunan Nyunyur), dan memuncaknya ekskalasi konflik di area eks-HGU di areal perkebunan tersebut, atau dengan lain kata, menjadikan tidak terkendalinya kondisi di areal perkebunan tersebut.

Masyarakat Desa Soso, enggan melakukan perjuangan agraria mereka dengan tuntutan lewat pengadilan karena kebanyakan mereka tidak memiliki bukti-bukti formal, seperti sertifikat. Perjuangan agraria yang mereka tempuh, yakni non-litigasi (di luar pengadilan) bahkan melalui jalur-jalur tekanan massa, lobbying politik melalui wakil-wakil rakyat DPRD Kabupaten Blitar. Lewat tekanan dan bargaining politik, lembaga politik menjadi ajang penyelesaian konflik hukum. Akan tetapi ketika kedua jalur tersebut buntu maka cara pendudukan seperti yang dilakukan pada tahun 2012 dengan membuat Kampung Merah Putih'33, secara paksa dilaksanaknan dengan harapan jalur ilegal ini akan berproses menjadi semi legal dan dari semi legal menjadi legal. ${ }^{14}$

Kasus yang terjadi seperti di Perkebunan Kismo Handayani, bukan tidak mungkin merupakan cerminan kasus nasional. Karena itu, harus seksama diperhatikan. Pemerintah Kab. Blitar dalam arti BPN Kab. Blitar, Pemkab Blitar, dan Pemerintah Desa Soso, Kec. Gandusari, Kab. Blitar melakukan berbagai upaya guna mengatasi ketidak terkendalinya kondisi di areal Perkebunan Kismo Handayani.

Sejak tahun 2009, Pemkab dan BPN Kab. Blitar sebagai pelaksana hukum, sebagai pewujud dari tujuan akhir sistem hukum yaitu keadilan guna mendistribusikan dan memelihara suatu alokasi nilai-nilai dalam masyarakat, dengan pandangan kebenaran ${ }^{15}$, mengupayakan penyelesaian masalah/sengketa di Perkebunan Kismo Handayani dengan membentuk tim fasilitasi penyelesaian masalah/sengketa. Namun, beragamnya persoalan

12 Soerabaia Newsweek. http://www.surabayanewsweek.com/2016/01/tanah-perkebunannyunyur-diklaim-milik.html. Diakses pada 15 Februari 2017.

${ }_{13}$ Pendudukan di areal sengketa pertanahan di Perkebunan Kismo Handayani ini, dilakukan oleh warga di areal perkebunan perusahaan. Kasus pendudukan di Kalimantan Tengah, menunjukkan sebaliknya. Justru, perusahaan melakukan pendudukan di area suci dan area komunal dan kemudian diubah menjadi kepemilikan pribadi. (Gama Galudra et.al, RaTA: A Rapid Land Tenure Assessment Manual for Identifying the Nature of Land Tenure Conflicts, Bogor, Indonesia : World Agroforestry Centre, 2010, p.30)

${ }_{14}$ Pendudukan areal sengketa pertanahan sebagai upaya perjuangan agaria, juga terjadi dalam konflik penguasaan tanah di Surabaya 1959-1967 (Arya W. Wirayuda, dari Klaim Sepihak hingga Land Reform, Konflik Penguasaan Tanah di Surabaya 1959-1967, Yogyakarta : STPN Press. 2011.

${ }^{15}$ Keadilan merupakan tujuan akhir sistem hukum sebagai sarana untuk mendistribusikan dan memelihara suatu alokasi nilai-nilai dalam masyarakat, yang ditanamkan dengan suatu pandangan kebenaran, yang secara umum merujuk kepada keadilan. Dyah Ochtorina Susanti, IGN Parikesit Widiateja, , Asas Keadilan, Konsep dan Implementasinya dalam Perspektif Hukum Islam dan Hukum Barat, Malang: Bayumedia Publishing, 2011, hal. 8. 
sengketa di perkebunan tersebut, tidak ada satu cara yang tepat. Hingga akhirnya tercapai mufakat dengan melakukan redistribusi lahan (eks)-HGU Perkebunan Kismo Handayani seluas lebih kurang 30 hektar kepada masyarakat Desa Soso, Kec. Gandusari, Kab. Blitar. Pada 26 November 2016 luasan lahan yang diredistribusi ini, sudah lebih dari tuntutan warga yang berdasarkan Surat Keputusan Menteri Pertanian dan Agraria Nomor : 49/Ka/1964.

Adanya kekhawatiran implikasi redistribusi tanah seperti dijual kepada orang lain, sehingga memungkinkan terjadi pemilikan tanah pada beberapa orang, maka pemerintah mesti menjadikan pelaksanaan redistribusi tanah tersebut dalam kerangka reforma agraria yang lengkap. Dalam arti, pemerintah harus terus mengontrol penggunaanya. Adanya koperasi rakyat sebagai pemegang hak penguasaan tanah yang disodorkan dalam konsep BPN-RI sebagai sarana delivery system yang telah dipraktekkan dan terbukti membawa kesejahteraan pada masyarakat di Desa Wangunwatie Kecamatan Karangnunggal Kabupataen Tasikmalaya, bisa menjadi salah satu referensi ${ }^{16}$. Selain hal tersbut, juga diperlukan kesediaan jajaran kantor pertanahan seperti Sub Seksi Pemberdayaan Masyarakat untuk berdialog dengan masyarakat penerima redistribusi di Desa Soso, Kec, Gandusari, Blitar tersebut, sehingga terbentuk kesadaran masyarakat tentang pengelolaan tanah (asset)-nya. ${ }^{17}$

Persoalan hak atas tanah Perkebunan Kismo Handayani sebagai tanah yang pernah masuk database sebagai tanah terindikasi terlantar (yang akhirnya tidak terbukti karena wujud pelaksanaan das sein-nya tidak sama dengan das sollen-nya), maka paska upaya penyelesaian konflik dengan meredistribusi lebih kurang 30 ha tanah areal (eks) HGU Perkebunan Kismo Handayani kepada warga Desa Soso sebagai solusi konflik di areal itu, status hak atas tanahnya harus segera jelas. Karena jika ketidakjelasan status hak atas tanah atas tanah tersebut terus berkepanjangan, sangat berbahaya karena bisa memicu munculnya konflik agraria stuktural. ${ }^{18}$

\section{PENUTUP}

Pelaksanaan Pasal 4 Ayat (1) Peraturan Pemerintah Republik Indonesia Nomor 11 Tahun 2010 tentang Penertiban dan Pendayagunaan Tanah Terlantar (PP 11/2010) di Kab.Blitar menjadikan tanah sengketa sebagai indikator tanah terindikasi terlantar (suatu pengindikasian tanah terindikasi terlantar yang tidak sesuai dengan substansi PP 11/2010).

Akibat pelaksanaan Pasal 4 Ayat (1) PP 11/2010 di Kab. Blitar yaitu: pelaksanaan PP 11/2010 di Kab. Blitar, terhenti pada tahap identifikasi dan penelitian; tidak ada satupun hak atas tanah di Kab. Blitar yang ditetapkan oleh Kepala BPN RI sebagai tanah terlantar,

${ }^{16}$ Deden Dani Saleh, "Dimensi Kepemimpinan Lokal dalam Menata Kelola Sumber Daya Agraria (Pengalaman Koperasi Wangunwatie Karangnunggal Tasikmalaya)", Bhumi, Jurnal Ilmiah Pertanahan PPPM-STPN, Nomor 4 Tahun 3, Maret 2011, hal. 118.

17 Suharno, dkk, "Minat Masyarakat Penerim Redistribusi Tanah terhadap Pensertipikatan Tanah (Studi di Kabupaten Kebumen Provinsi Jawa Tengah)", Bhumi, Jurnal Ilmiah Pertanahan PPPMSTPN, Nomor 2 Tahun 2, Maret 2010, hal. 68.

18 Noer Fauzi Rahman, "Rantai Penjelas Konflik-Konflik Agraria yang Kronis, Sistemik, dan Meluas di Indonesia", Bhumi, Jurnal Ilmiah Pertanahan PPPM-STPN, Nomor 37 Tahun 12, April 2013, hal. 1. 
ketidakjelasan status hukum hak atas tanah perkebunan Kismo Handayani selama \pm 6 tahun ( 2011-2016 ); dan memuncaknya ekskalasi konflik di area eks-HGU Perkebunan Kismo Handayani dalam rentang waktu tahun 2011-2016.

Pelaksanaan Pasal 4 ayat (1) PP 11/2010 di Kab. Blitar, seyogyanya dilaksanakan sesuai dengan substansi hukumnya, agar terselesaikan masalah yang melatarbelakangi pembentukannya, karena pelaksanaan (tindakan stuktur hukum) yang tidak sesuai dengan subtansi hukum, hanya akan berimplikasi pada munculnya permasalahan baru.

Pasca pengupayaan penyelesaian di Perkebunan Kismo Handayani, BPN Kab. Blitar, Pemkab Blitar, Dinas Pertanian/Perkebunan Kab. Blitar, sebagai birokrasi pewujud keadilan sosial di wilayah Kab. Blitar, harus senantiasa dapat mengupayakan upaya-upaya untuk menghadirkan Pancasila, konstitusi dan paham konstitusionalisme yang sanggup memberi arah dan inspirasi bagi usaha-usaha mewujudkan keadilan agraria, yakni kondisi dimana tidak terdapat konsentrasi yang berarti dalam penguasaan, pemilikan, penggunaan, dan pemanfaatan tanah, kekayaan alam, dan wilayah hidup rakyat pedesaan, dan terjaminya hak-hak petani dan pekerja petani lainnya atas akses dan kontrol terhadap tanah, kekayaan alam, dan wilayah hidupnya. Dan akhirnya, setelah penelitian ini selesai terkerjakan (Februari 2017), telah terbitlah sertifikat HGU atas nama Kismo Handayani 2017. 


\section{DAFTAR PUSTAKA}

Buku

Abdurrahman, Tebaran Pikiran tentang Studi Hukum dan Masyarakat, Jakarta : Media Sarana Press, 1986.

Ashshofa, Burhan, Metode Penelitian Hukum, Jakarta : PT Rineka Cipta, 2004.

Asshiddiqie, Jimly, "Struktur Hukum dan Hukum Struktural Indonesia", dalam Dinal Fedrian dkk, Dialektika Pembaharuan Sistem Hukum Indonesia, Jakarta: Komisi Yudisial Republik Indonesia, 2012.

Bernstein, Henry et.al, Kebangkitan Studi Reforma Agraria di Abad 21, Yogyakarta : STPN Press, 2008.

Borras Jr, Saturnino M, dkk, Gerakan-Gerakan Agraria Transnasional, Yogyakarta : STPN, 2010.

Busroh, Abu Daud. Capita Selecta Hukum Tata Negara, Jakarta : Rineka Cipta. 1994,

Friedman, Lawrence, M., Sistem Hukum Perspektif Ilmu Sosial. Bandung : Penerbit Nusamedia, 2011.

The Legal System; A Social Scince Prespective, New York : Russel Sage Foundation, 1975.

Teori Filsafat Hukum, Telaah Kritis atas Teori-Teori Hukum (Susunan I), Penerjemah, Muhammad Arifin. Judul Asli : Legal Theory, Jakarta Utara: Rajawali Pers, 1990.

Teori dan Filsafat Hukum. Hukum dan masalah2 kontemporer

(Susunan III). Jakarta : Rajawali Pres. Judul asli : Legal Theory, 1990.

Galudra, Gamma, dkk, Rata : Manual Penilaian Cepat Konflik Pertanahan, Yogyakarta : STPN Press, 2013.

Galudra, Gama, dkk, RaTA: A Rapid Land Tenure Assessment Manual for Identifying the Nature of Land Tenure Conflicts, Bogor, Indonesia : World Agroforestry Centre, 2010.

Harsono, Boedi, Hukum Agraria Indonesia Sejarah Pembentukan Undang-Undang Pokok Agraria Isi dan Pelaksanaannya Jilid 1 Hukum Tanah Nasional, Jakarta : Djambatan, 1999.

Ibrahim, Johnny, Teori dan Metodologi Penelitian Hukum Normatif, Malang : Bayumedia Publishing, 2011.

Iver, MC., Jaring-Jaring Pemerintahan, Jakarta : AKSARA BARU, 1983.

Kansil, C.S.T, Hukum Tata Negara Republik Indonesia, Jakarta : PT Rineka Cipta. 2000.

Kelsen, Hans, Teori Umum tentang Hukum dan Negara, Bandung : Nusa Media. 2011.

Li, Tania M., The Will to Improve: Governemntality, Development, and Practice of Politics, Duke University Press, 2007.

Lopa, Baharuddin, Permasalahan Pembinaan dan Penegakan Hukum di Indonesia, Jakarta: Bulan Bintang, 1987.

Luthfi, A.N.; Farhan, Mahfuzi; Iftitah, Anik, Menerjemahkan secara Teknis Kendala Penertiban Tanah Terlantar di Kabupaten Blitar, Yogyakarta : PPPM STPN. 2013.

Luthfi, Ahmad Nashih, , Panduan Mutu Penelitian Terkendali, Yogyakarta : STPN Press. 2012.

Luthfi, Ahmad Nashih, dkk, Kondisi dan Perubahan Agraria Desa Ngandagan di Jawa Tengah Dulu dan Sekarang, Yogyakarta : STPN Press, 2013.

Manan, Bagir, Beberapa Masalah Hukum Tata Negara Indonesia, Bandung : P.T. ALUMNI, 1997.

Marbun, SF dkk, Dimensi-Dimensi Pemikiran Hukum Administrasi Negara, Yogyakarta : UII Press, 2001. 
Mas, Marwan, Pengantar Ilmu Hukum, Jakarta : Ghalia Indonesia, 2004.

Mertokusumo, Sudikno, Penemuan Hukum Sebuah Pengantar, Yogyakarta : Liberty, 1996.

Moleong, , Metode Penelitian Kualitatif, Bandung : Remaja Rosda Karya, 2000.

Mucshin, Ikhtisar Materi Pokok Filsafat Hukum, Depok : STIH "Iblam", 2004.

Muttaqien, Andi, dkk, Wajah Baru Agrarische Wet, Jakarta Selatan : Elsam-Sawit WatchPilnet, 2012.

Nugraho, Aristiono, dkk, Resonansi Landreform Lokal Dinamika Pengelolaan Tanah di Desa Karanganyar, Yogyakarta : STPN-Press, 2013.

Pusat Penelitian dan Pengabdian kepada Masyarakat Sekolah Tinggi Pertanahan Nasional, , Pedoman Teknis Penulisan Proposal dan Laporan Penelitian, Yogyakarta : STPN. 2011.

Puspa, Yan Pramadya, Kamus Hukum, Semarang : CV Aneka Ilmu. 2008.

Rachman, Noer Fauzi, Land Reform Dari Masa ke Masa, Yogyakarta : Tanah Air Beta, 2012 ,

Rahardjo, Satjipto, Ilmu Hukum, Bandung : Alumni, 1982.

Rasjidi, Lili dan Putra, I.B. Wyasa, 2003, Hukum sebagai Suatu Sistem, Bandung : Mandar Maju.

Rasjidi, Lili, Dasar-Dasar Filsafat Hukum, Bandung : PT. Citra Aditya, 1990.

Rianto, Adi , Metodologi Penelitian Sosial dan Hukum, Jakarta : Granit, 2004.

Rosset, Peter, dkk, Reforma Agraria Dinamika Aktor dan Kawasan, Yogyakarta : STPN Press, 2008.

Sabon, Max Boli, Ilmu Negara, Jakarta : Gramedia Pustaka Utama, 1992.

Sinaga, Budiman N.P.D., Ilmu Pengetahuan Perundang-undangan, Yogyakarta : UII Press, 2005.

Soekanto, Soejono, Faktor-Faktor yang Mempengaruhi Penegakan Hukum, Jakarta : PT Raja Grafindo Persada, 2005.

Soekanto, Soerjono; Mamuji, Sri, Penelitian Hukum Normatif Suatu Tinjauan Singkat, Jakarta : PT Raja Grafindo Persada, 2004.

Soemitro, Ronny Hanitiyo, Studi Hukum dan Masyarakat, Bandung : Alumni, 1982.

Soeprapto, Maria Farida Indrati, Ilmu Perundang-Undangan Dasar-Dasar dan Pembentukannya, Yogyakarta : Kanisius, 1996.

Sumaryono, Eugenius, Filsafat Hukum (Sebuah Pengantar Singkat), Yogyakarta : Universitas Atma Jaya Yogyakarta. 1989.

Hartono, Sunaryati, Politik Hukum Menuju Satu Hukum Nasional, Jakarta : Alumni. 1991

Sunggono, Bambang, Metodologi Penelitian Hukum, Jakarta : PT Raja Grafindo Persada, 2005.

Susanti, Dyah Ochtorina, Widiateja IGN Parikesit, Asas Keadilan, Konsep dan Implementasinya dalam Perspektif Hukum Islam dan Hukum Barat, Malang : Bayumedia Publishing, 2011.

Sutaryono, Kontestasi dan Marginalisasi Petani Realitas Petani Negeri Agraris, Taman Sidoarjo, Surabaya : Zifatama, 2013.

Syahrani, Riduan, , Rangkuman Intisari Ilmu Hukum, Banjarmasin : Pustaka Kartini. 1991.

Syaukani, Imam; Tohari, A. Ahsin, Dasar-Dasar Politik Hukum, Jakarta : PT Raja Grafindo Persada, 2004.

Tanzeh, Ahmad, Pengantar Metode Penelitian, Yogyakarta : Teras. 2009.

Tim Peneliti STPN, Kebijakan, Konflik dan Perjuangan Agraria Indonesia Awal Abad 21, Yogyakarta : STPN Press, 2012.

Tim Peneliti STPN, Membaca Ulang Politik dan Kebijakan Agraria, Yogyakarta : STPN Press , 2013.

Vollenhoven, Cornelis Van, Orang Indonesia dan Tanahnya. Yogyakarta : STPN Press, 2013. 
Winarta, Frans Hendra, "Membangun Profesionalisme Aparat Penegak Hukum", dalam Dinal Fedrian dkk, Dialektika Pembaharuan Sistem Hukum Indonesia, Jakarta: Komisi Yudisial Republik Indonesia, 2012.

Wiradi, Gunawan, Seluk Beluk Masalah Agraria Reforma Agraria dan Penelitian Agraria, Yogyakarta : STPN Press, 2009.

Wirayuda, Arya W., dari Klaim Sepihak hingga Land Reform, Konflik Penguasaan Tanah di Surabaya 1959-1967, Yogyakarta : STPN Press, 2011.

Yayasan Lembaga Bantuan Hukum Indonesia dan AusAID, Panduan Bantuan Hukum di Indonesia, Pedoman Anda Memahami dan Menyelesaikan Masalah Hukum, Jakarta : Yayasan Obor Indonesia, 2014.

Jurnal

Dicky Firmansyah, "Pendayagunaan Tanah Terlantar untuk Kesejahteraan Rakyat", Bhumi, Jurnal Ilmiah Pertanahan PPPM-STPN, Nomor 3 Tahun 2, September 2010, 2010.

Deden Dani Saleh, "Dimensi Kepemimpinan Lokal dalam Menata Kelola Sumber Daya Agraria (Pengalaman Koperasi Wangunwatie Karangnunggal Tasikmalaya)", Bhumi, Jurnal Ilmiah Pertanahan PPPM-STPN, Nomor 4 Tahun 3, Maret 2011.

Suharno, dkk, "Minat Masyarakat Penerim Redistribusi Tanah terhadap Pensertipikatan Tanah (Studi di Kabupaten Kebumen Provinsi Jawa Tengah)", Bhumi, Jurnal Ilmiah Pertanahan PPPM-STPN, Nomor 2 Tahun 2, Maret 2010.

Noer Fauzi Rahman, "Rantai Penjelas Konflik-Konflik Agraria yang Kronis, Sistemik, dan Meluas di Indonesia", Bhumi, Jurnal Ilmiah Pertanahan PPPM-STPN, Nomor 37 Tahun 12, April 2013.

Borras Jr, Saturnino M. dan Jennifer C. Franco, “Contemporary Discourses and Contestations around Pro-Poor Land Policies and Land Governance", Journal of Agrarian Change, Vol. 10 No. 1, Januari 2010.

Peraturan Perundang-Undangan:

Undang-Undang Dasar Negara Republik Indonesia 1945

Undang-Undang Nomor 5 Tahun 1960 tentang Peraturan Dasar Pokok-Pokok Agraria

Undang-Undang Nomor 12 Tahun 2011 tentang Pembentukan Peraturan Perundangundangan

Peraturan Pemerintah Nomor 11 Tahun 2010 tentang Penertiban dan Pendayagunaan Tanah Terlantar

Internet

BlitarTimes.http://www.timesindonesia.co.id/baca/110093/20151201/195351/fppmtuntut-langkah-solutif-konflik-perkebunan-nyunyur/.

Soerabaia Newsweek. http:/ /www.surabayanewsweek.com/2016/01/tanah-perkebunannyunyur-diklaim-milik.html. 